\begin{abstract}
BACKGROUND and aim: Macrolide antibiotics are widely used in the treatment of suppurative lung diseases including cystic fibrosis (CF), the most common inherited fatal disease in the Caucasian population. This condition is characterized by secondary Pseudomonas infection resulting in neutrophil infiltration within the airways. The aim of the study was to investigate the evolution of inflammatory process in $C F$ patients receiving long-term clarithromycin therapy.

Methods: Twenty-seven CF patients (mean age, 12 years) were enrolled into the study. Beside the basic therapy the patients were treated with clarithromycin at a dose of $250 \mathrm{mg}$ every other day orally. All patients were routinely examined every 3 months. Blood and sputum were collected before clarithromycin treatment and then again 3,6 and 12 months after the drug prescription. Cytokine concentrations (tumor necrosis factor- $\alpha$, interleukin-8, interleukin-4, interferon- $\gamma$ ) in the sputum and plasma were assayed. Peripheral blood lymphocyte response to phytohemagglutinin was also evaluated.

Results: Clarithromycin treatment resulted in a marked reduction of the cytokine levels both in the sputum and plasma specimens. At the same time, the interferon- $\gamma /$ interleukin- 4 ratio has been significantly elevated. In addition, a sustained increase of peripheral blood lymphocyte response to phytohemagglutinin was demonstrated. These changes were associated with a significant improvement of the lung function.

Conclusions: The beneficial effect of the prolonged treatment of CF patients with a 14-membered ring macrolide antibiotic clarithromycin seems to be associated not only with down-regulation of the inflammatory response, but also with immunological changes including the switch from Th2 to Th1 type response.
\end{abstract}

Key words: Clarithromycin, Cystic fibrosis, Cytokines, Interferon- $\gamma$, Interleukin-4, Lymphocyte proliferation, Macrolides, Tumor necrosis factor- $\alpha$, Th1 type response

\section{Anti-inflammatory and immunomodulating effects of clarithromycin in patients with cystic fibrosis lung disease}

\author{
Alexander L. Pukhalsky ${ }^{\text {CA }}$, Galina V. Shmarina, \\ Nikolai I. Kapranov, Svetlana N. Kokarovtseva, \\ Daria Pukhalskaya and Natalia J. Kashirskaja
}

Research Centre for Medical Genetics, 1 Moskvorechie Street, Moscow, 115478, Russia

\footnotetext{
${ }^{\mathrm{CA}}$ Corresponding author

Tel: +70951118568

Fax: + 70953240702

E-mail: osugariver@medgen.ru
}

\section{Introduction}

Clarithromycin belong to an antibiotic family referred to as macrolides, which is well known since the erythromycin introduction into antibacterial therapy. All macrolides are lactone monocycles, which include from 12 to 23 atoms of carbon, but molecules used as a drug have commonly 14, 15 or 16 atoms. There are numerous reports of 14-membered and 15membered ring macrolide antibiotics having antiinflammatory activity. It has been suggested that macrolides affect the migration of neutrophils and inhibit the neutrophil oxidant burst. ${ }^{1-4}$ Furthermore, macrolides have been shown to impair the production of pro-inflammatory cytokines, such as interleukin (IL)-6, IL-8, IL-1 $\beta$, and tumor necrosis factor
(TNF)- $\alpha$, by cultured human bronchial epithelial cells ${ }^{5,6}$ and in whole blood. ${ }^{7}$ Modification of cytokine production by macrolides has been explored also in ex vivo experiments. It was shown in mice that longterm treatment ( 42 days) with roxithromycin caused a significant decrease of IL-1, IL-2 and IL-5 production. ${ }^{8,9}$ Moreover, there were a marked reduction of TNF- $\alpha$, IL- 6 , and macro phage inflammatory protein1a (MIP- $\alpha$ ) concentrations in the lung of mice infected with Mycoplasma pneumoniae after the course of clarithromycin. ${ }^{10}$ For a review see also Labro $^{11}$ and Jaffé and Bush. ${ }^{12}$

There is extensive literature on the subject of the beneficial effect of macrolide antibiotics in patients with suppurative lung diseases including diffuse panbronchiolitis (DPB) and cystic fibrosis (CF); the 
latter is the most common inherited fatal disease in the Caucasian population. Both conditions are characterized by secondary Pseudomonas infection resulting in neutrophil infiltration within the airways. The prognosis of DPB has been dramatically improved in recent years. Thus, the 10-year mortality of $80 \%$ for this disorder was by chance found to be reduced to only $10 \%$ by the administration of erythromycin and some other macrolides. ${ }^{13,14}$ There is clinical evidence to support the use of macrolide antibiotics in CF treatment. A significant increase in both forced vital capacity (FVC) and forced expiratory volume in $1 \mathrm{sec}\left(\mathrm{FEV}_{1}\right)$ following treatment was shown. ${ }^{15-18}$ Nevertheless, the underlying mechanisms are not yet fully understood. Besides the inflammatory cytokine and oxidant production, other possible target for these drugs must not be ruled out.

This study aimed to investigate the evolution of inflammatory process in CF patients receiving longterm clarithromycin therapy.

\section{Patients and methods}

\section{Subjects}

Twenty-seven patients (mean age, $12.0 \pm 0.6$ years) from the Cystic Fibrosis Department of the Research Centre for Medical Genetics (Moscow) were enrolled into the study. CF was diagnosed by increased chloride concentrations $(>60 \mathrm{mmol} / \mathrm{l})$ in a sweat test and typical clinical symptoms of the disease, and/ or detection of mutations in both CFTR alleles. The patient characteristics are presented in Table 1 . The CFTR genotype in $27 \mathrm{CF}$ patients was homozygous for $\Delta$ F508 mutation in seven individuals and heterozygous in 10 individuals. Five patients had mutations other than $\Delta \mathrm{F} 508$, and in five cases not one in known mutations has been revealed. Thirteen individuals were chronically colonized with the mucoid form of Pseudomonas aeruginosa. $\mathrm{FEV}_{1}$ and $\mathrm{FVC}$ values averaged $65.7 \pm 4.4$ and $76.2 \pm 4.0 \%$ predicted, respectively. The patients were treated with basic therapy (mucolytics, multivitamins, high calorie diet, microspheric enzymes) and clarithromycin (KLACID ${ }^{\circledR}$; Abbott Laboratories, Abbott Park, Ill, USA), which was prescribed in the dose of $250 \mathrm{mg}$ every other day. In the case of acute pulmonary exacerbation, antibacterial treatment depended on the microbiology analysis of the sputum. Individuals with P. aeruginosa infection were treated by cephalosporins of third generation in combination with aminoglycosids or ciprofloxacin. The patients were examined before drug prescription and then again every 3 months. Subjects with chronic $P$. aeruginosa infection and poor lung function ( $\mathrm{FVC}$ and $\mathrm{FEV}_{1}<70 \%$ predicted) were evaluated after a 2 -week routine antibiotic course. The patients who demonstrated relatively good lung function were examined at a time of wellbeing during an ordinary visit to the department.

Table 1. Characteristics of the study patients

\begin{tabular}{|c|c|c|c|c|c|}
\hline Age (years) & Sex & Mutation & P. aeruginosa & FVC (\% predicted) & $\mathrm{FEV}_{1}(\%$ predicted $)$ \\
\hline 10 & Male & $\Delta \mathrm{F} 508 / \Delta \mathrm{F} 508$ & No & 88.9 & 74.9 \\
\hline 13 & Female & $-1-$ & No & 103.4 & 99.4 \\
\hline 17 & Male & $\Delta$ F508/CFTRdele2,3 (21 kb) & Yes & 82.8 & 71.8 \\
\hline 14 & Male & $-1-$ & No & 88.3 & 74.1 \\
\hline 15 & Female & $-/ 2184$ ins A & Yes & 57.7 & 46.5 \\
\hline 14 & Male & $\Delta \mathrm{F} 508 / \Delta \mathrm{F} 508$ & No & 89.3 & 77.8 \\
\hline 11 & Female & $\Delta \mathrm{F} 508 / \Delta \mathrm{F} 508$ & Yes & 57.5 & 43.4 \\
\hline 16 & Male & $-1-$ & No & 89.4 & 81.8 \\
\hline 8 & Male & $\Delta \mathrm{F} 508 /$ dele? $(\mathrm{ex} 13)^{*}$ & Yes & 81.4 & 74.5 \\
\hline 6 & Female & $\Delta \mathrm{F} 508 / \Delta \mathrm{F} 508$ & No & 111.1 & 103.6 \\
\hline 14 & Female & $\Delta \mathrm{F} 508 / \Delta \mathrm{F} 508$ & Yes & 48.7 & 40.3 \\
\hline 11 & Male & W1282R(ex20)/- & Yes & 63.5 & 34.6 \\
\hline 13 & Female & $\Delta \mathrm{F} 508 / \mathrm{W} 1282 \mathrm{X}$ & No & 66.6 & 44.9 \\
\hline 11 & Female & $\Delta \mathrm{F} 508 /-$ & Yes & 56.0 & 40.7 \\
\hline 16 & Male & -/394delTT & No & 54.1 & 45.4 \\
\hline 12 & Male & $\Delta \mathrm{F} 508 /-$ & Yes & 68.3 & 54.1 \\
\hline 7 & Female & $\Delta \mathrm{F} 508 /-$ & Yes & 67.8 & 64.2 \\
\hline 11 & Male & $\Delta$ F508/CFTRdele2,3 (21 kb) & No & 78.5 & 65.9 \\
\hline 11 & Female & $-/ G 542 X$ & Yes & 32.6 & 22.9 \\
\hline 14 & Female & $-1-$ & Yes & 82.8 & 58.0 \\
\hline 8 & Male & $-/ 3821 \mathrm{delT}(19 \mathrm{ex})$ & Yes & 65.7 & 61.4 \\
\hline 16 & Female & $\Delta \mathrm{F} 508 / \Delta \mathrm{F} 508$ & No & 94.8 & 91.6 \\
\hline 10 & Male & $\Delta \mathrm{F} 508 /-$ & No & 101.2 & 96.9 \\
\hline 15 & Female & $\Delta \mathrm{F} 508 / \mathrm{N} 1303 \mathrm{~K}$ & Yes & 46.9 & 39.0 \\
\hline 11 & Male & $-1-$ & No & 117.1 & 102.8 \\
\hline 11 & Female & $\Delta \mathrm{F} 508 / \Delta \mathrm{F} 508$ & No & 87.2 & 87.8 \\
\hline 10 & Female & $\Delta$ F508/CFTRdele2,3 (21 kb) & No & 80.9 & 76.4 \\
\hline
\end{tabular}

Results of pulmonary function tests (forced expiratory volume in $1 \mathrm{sec}$ and forced vital capacity) are expressed as a percentage of predicted values for age, sex, and height. * Unidentified deletion in exon $13 ;-$, an unknown mutation. 


\section{Blood collection and sputum processing}

Blood was collected in tubes with heparin $(25 \mathrm{IU} / \mathrm{ml})$ by venopuncture. The sputum samples were placed into the container with ice and delivered to the laboratory within $1 \mathrm{~h}$. The weight of each sputum sample was calculated. The same weight of phosphate-buffered saline without $\mathrm{Ca}^{2+}$ and $\mathrm{Mg}^{2+}$ was added to the sputum sample. The mixture placed on vortex for $10 \mathrm{sec}$ and then on the rocker for $30 \mathrm{~min}$. The sample was filtered through a $100 \mu \mathrm{m}$ filter to remove mucus. The filtrate has been centrifuged at $400 \times g$ for $10 \mathrm{~min}$ at $4^{\circ} \mathrm{C}$ to pellet the cells. The supernatant has been harvested, aliquoted and stored at $-60^{\circ} \mathrm{C}$. Protein concentrations in the samples were measured by Bradford's method. ${ }^{19}$

\section{Peripheral blood lymphocyte response to phytohemagglutinin}

Heparinized peripheral blood was centrifuged and plasma was collected, aliquoted and stored at $-60^{\circ} \mathrm{C}$. The cell pellet was resuspended in phosphatebuffered saline and mononuclear cells were isolated by Ficoll-Verographin density gradient centrifugation. The cells were washed twice and resuspended in RPMI-1640 medium supplemented with 10\% heatinactivated donor horse serum, $2 \times 10^{-3}$ M HEPES, $2 \mathrm{mM}$ L-glutamine, $2.8 \times 10^{-6} \mathrm{M} 2$-mercaptoethanol, and $20 \mu \mathrm{g} / \mathrm{ml}$ gentamycin. The cells were cultivated in flat-bottomed 96-well plates, and contained $5 \times$ $10^{4}$ cells in each well. The final concentration of phytohemagglutinin (PHA) was $5 \mu \mathrm{g} / \mathrm{ml}$. The cells were incubated for $72 \mathrm{~h}$ at $37^{\circ} \mathrm{C}$ in a humidified atmosphere containing 5\% $\mathrm{CO}_{2}$. Four hours before the end of cultivation, each well was pulsed with 40 $\mathrm{kBq}$ of $\left[{ }^{3} \mathrm{H}\right]$-thymidine. The cells were harvested with a cell harvester and counted on a liquid scintillation counter. Triplicate wells were assayed and the counts per minute were averaged.

\section{Assay of human leukocyte elastase activity}

The method is based on the ability of neutrophil elastase to interact with the specific chromogenic substrate $N$-methoxysuccinyl-ala-ala-pro-val $p$-nitro anilide (Sigma, St Louis, MO, USA), forming a colored complex with maximum of absorbance at 410 $\mathrm{nm} \cdot{ }^{20,21}$ The standard assay was performed in $1 \mathrm{ml}$ of a solution containing an aliquot of sputum sample (10-20 $\mu \mathrm{l}), 0.003 \mathrm{M}$ substrate $(100 \mu \mathrm{l})$ and $0.1 \mathrm{M}$ Tris containing $0.5 \mathrm{M} \mathrm{NaCl}$ (up to $1 \mathrm{ml}$ ) at $\mathrm{pH}$ 7.6-7.8. Probes were assayed for absorbance every $20 \mathrm{sec}$ during $3 \mathrm{~min}$ at $25^{\circ} \mathrm{C}$. Then absorbance per minute was accounted. The amount of elastase was calculated using the formula:

$$
\text { Elastase activity }(\mathrm{U} / \mathrm{ml})=D_{410} \times 102 / V
$$

where $\mathrm{D}_{410}$ is the absorbance per minute, $V$ is the volume of the sputum aliquot added, and 102 is a parameter that includes the extinction coefficient, the length of light path, and volume of the reaction mixture. Under this specified condition, $1 \mathrm{U}$ of human neutrophil elastase activity was that amount that hydrolyzed $1 \mathrm{nM}$ of substrate per minute. Finally, the value of neutrophil elastase activity was normalized to the protein content in each sample of the sputum extract.

\section{Cytokine assays}

The TNF- $\alpha$ level in plasma was estimated using commercially available kit (CYTOKINE, St Peter sburg, Russia).

TNF- $\alpha$ activity in sputum specimens was determined by the method of Ruff and Gifford ${ }^{22}$ with some modifications. Briefly, murine fibroblastoma cells (L929 cell line) were seeded at a density $3 \times 10^{4}$ cells per well in 96-well plates in $100 \mu$ of medium 199 to which 10\% heat-inactivated calf bovine serum and gentamycin had been added. Plates were incubated at $37^{\circ} \mathrm{C}$ in a humidified atmosphere containing $5 \%$ $\mathrm{CO}_{2}$ until the monolayer formation. After the culture medium elimination, two-fold serial dilution of the samples (100 $\mu \mathrm{l}$ of each dilution) and $100 \mu \mathrm{l}$ of fresh culture medium with $20 \mu \mathrm{g} / \mathrm{ml}$ of actinomycin D were added, and further incubated for $18 \mathrm{~h}$ at the same conditions. Supernatants were then removed and cells stained with $0.2 \%$ crystal violet (Sigma). After washing and drying the plates were finally read at 595 $\mathrm{nm}$ on a microplate reader. Human recombinant TNF- $\alpha$ (Institute of Bioorganic Chemistry, Moscow, Russia) was used as internal standard. For the comparison of experimental and calibrating curves the probit-analysis method was used. The TNF- $\alpha$ content in the samples was normalized to the protein content in each sputum sample and expressed in IU/ mg protein (1 $\mathrm{IU}=13.3 \mathrm{pg})$.

Plasma and sputum samples were analyzed for IL-4, IL-8, and IFN- $\gamma$ by enzyme-linked immunosorbent assay technique with commercially available kits (CYTOKINE).

\section{Ethics}

The study was approved by the Ethics Committee of the Research Centre for Medical Genetics. All patients (or their parents) gave written informed consent to all parts of the study.

\section{Statistical analysis}

The effect of clarithromycin treatment on PHAinduced peripheral blood lymphocyte proliferation was evaluated using Student's $t$-test. The differences in annual changes in $\mathrm{FEV}_{1}$ and $\mathrm{FVC}$ before and after 
clarithromycin treatment were evaluated by the Student's $t$-test for paired data. For investigating differences between cytokine concentrations in the sputa and in the plasma specimens, statistical analysis was performed using non-parametric Wilcoxon tests.

\section{Results}

\section{Pulmonary function tests}

During 1 year before the start of clarithromycin, most patients had experienced a decline in $\mathrm{FEV}_{1}$ and FVC. Following the drug treatment a significant increase of the annual values of $\mathrm{FEV}_{1}$ and $\mathrm{FVC}$ has been observed (Fig. 1).

\section{In situ inflammatory markers}

Long-term oral administration of clarithromycin was associated with a sustained reduction of the sputum TNF- $\alpha$ level (Fig. 2A). Thus, a marked decrease of the cytokine concentration was already observed after 3 months of the treatment (median, 3.9 compared with $17.3 \mathrm{IU} / \mathrm{mg}$ protein; $p=0.05$ ). Sputum TNF- $\alpha$ was again elevated in the point of ' 6 months' but its level remained significantly lower than the initial value (median, $8.2 \mathrm{IU} / \mathrm{mg}$ protein; $p=0.02$ ). However, a marked reduction of the sputum TNF- $\alpha$ has been found after 1 year of the treatment (median, $0.71 \mathrm{IU} /$ mg protein; $p<0.001$ ).

The alterations in IL- 8 level seemed to be less dramatic (Fig. 2B). Similar to TNF- $\alpha$, a decrease in the cytokine concentration was found after 3 months of the treatment (median, $2.7 \mathrm{pg} / \mathrm{mg}$ of protein; $p=$ 0.03). After a 6-month course of clarithromycin, IL-8 concentrations in the sputa did not significantly differ from the initial levels (median, 5.94; $p=0.13$ ). Nevertheless, there was two-fold reduction of the cytokine

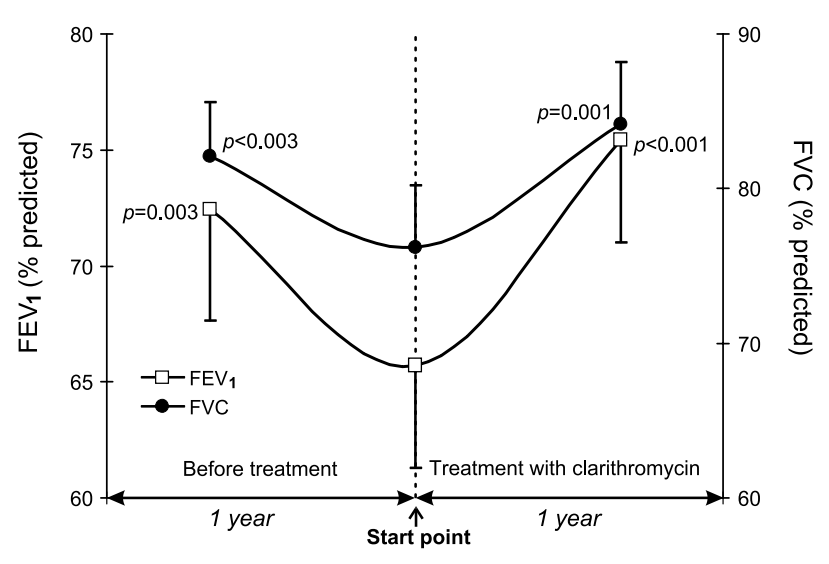

FIG. 1. Pulmonary function test results. The data are presented as mean values of forced vital capacity (FVC) and forced expiratory volume in $1 \mathrm{sec}\left(F E V_{1}\right)$. The results were analyzed using a paired $t$-test. concentration in the end of the study (median, 2.3 $\mathrm{pg} / \mathrm{mg}$ of protein; $p=0.03$ ). It has been noted that both pro-inflammatory cytokines, TNF- $\alpha$ and IL-8, demonstrated a marked reduction after 3 months of the treatment. This effect seems to be related in part with season fluctuations of in situ inflammatory markers commonly observed in patients with chronic lung disease. Indeed, in our study the point of ' 3 months' fell in June whereas the next sputum collection was performed in October, a relatively cold month in Moscow.

Figure 2C illustrates the changes of IFN- $\gamma$ levels in the sputum specimens. There were no significant alterations in the cytokine concentrations during 6month treatment with clarithromycin (medians for 0 , 3 , and 6 months, 31.6, 27.5, and $44.7 \mathrm{pg} / \mathrm{mg}$ of protein, respectively). In the same time over 1 year, the cytokine became undetectable in the sputum specimens of the most patients.

As can be seen in Figure 2D, the drop of the sputum IL-4 was most sustained and pronounced. Thus, a 10-fold decrease of the cytokine concentration has been demonstrated beginning at the sixth month of observation (medians for 0,6 , and 12 months, $41.8,3.0$, and $5.9 \mathrm{pg} / \mathrm{mg}$ of protein, respectively; both $p<0.01$ )

We failed to find significant changes both in neutrophil elastase activity and protein concentration in the sputum specimens during clarithromycin treatment (Table 2).

\section{Inflammatory markers in peripheral blood}

Figure $3 \mathrm{~A}$ illustrates changes in plasma IL-4 during the course of clarithromycin. We found a marked decrease in the cytokine concentration after 6 months of the treatment (median, 25.5 compared with 48.5 $\mathrm{pg} / \mathrm{ml} ; p=0.002$ ). Over 1 year a 10 -fold reduction of the cytokine level has been shown (median, $3.4 \mathrm{pg} /$ $\mathrm{ml} ; p<0.001$ ). With regard to plasma IFN- $\gamma$, median values were $91.7,141.8$ and $22.3 \mathrm{pg} / \mathrm{ml}$ before and after 6 and 12 months, respectively. However, these changes did not reach significance (Fig. 3B).

IL- 8 and TNF- $\alpha$ levels were undetectable in plasma samples of the most patients during all the observation period (the data are not presented).

Before the treatment the patients demonstrated relatively low T-cell response to PHA. Clarithromycin administration resulted in a sustained increase of peripheral blood lymphocyte proliferation (Table 3). The most prominent elevation of the cell response to PHA was revealed 3 months after the start of the treatment. The same as pro-inflammatory cytokines (IL- 8 and TNF- $\alpha$ ) in the sputum, such an increase of peripheral blood lymphocyte proliferation seems to be associated with the season changes of inflammatory markers (blood collection was performed in June). A marked but not so prominent elevation of 
(A)
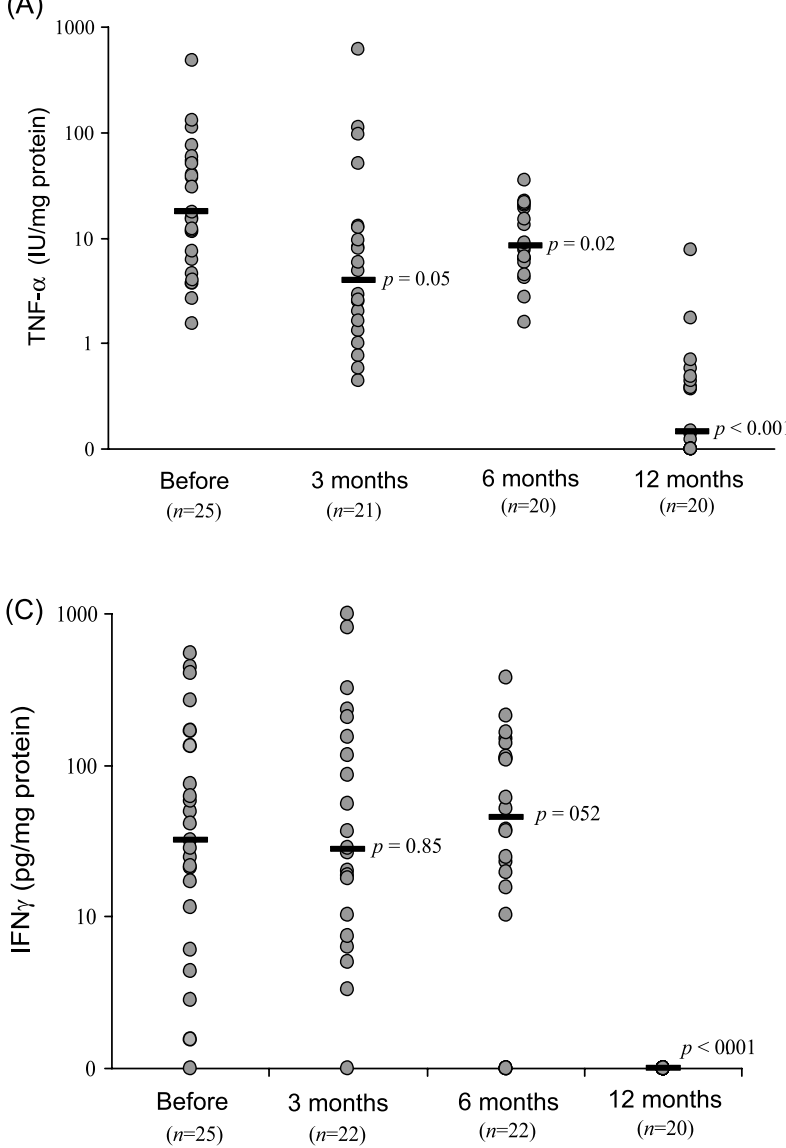

(B)

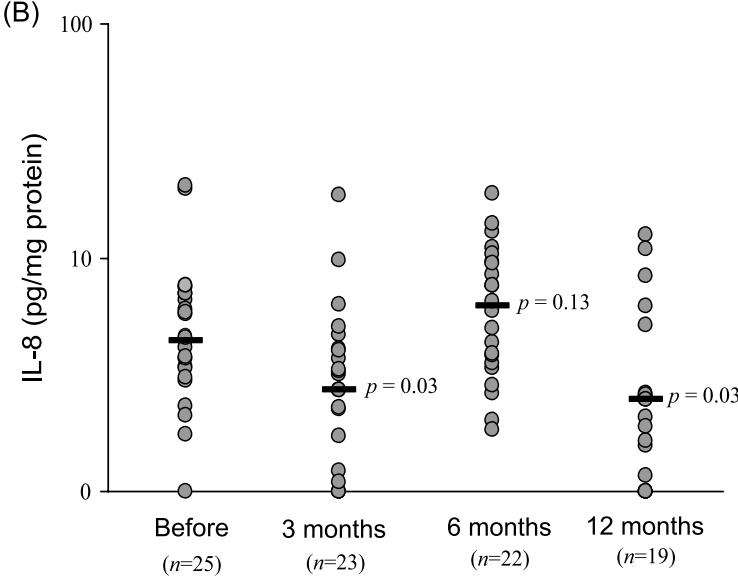

(D)

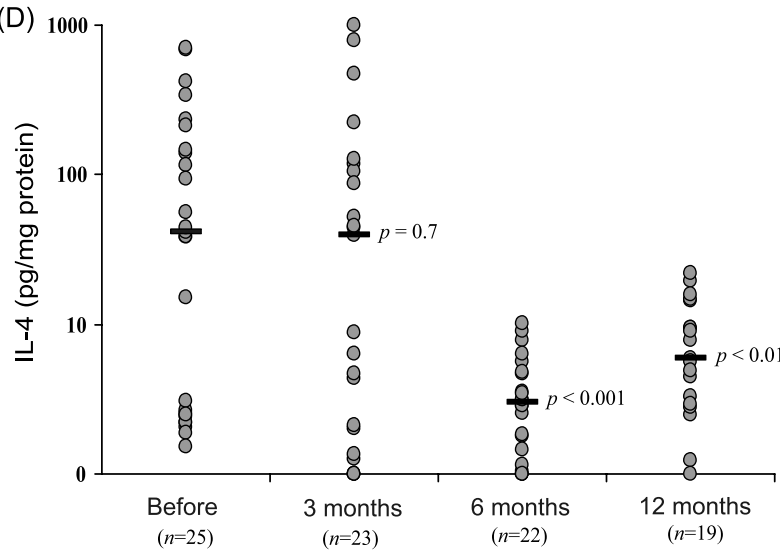

FIG. 2. Cytokine concentrations in the sputum during clarithromycin treatment. Sputum specimens were assayed for TNF- $\alpha$ (A), IL-8 (B), IFN- $\gamma($ C), and IL-4 (D). Median values are indicated by the lines. Each dot represents one subject. A two-sample Wilcoxon test was used to compare the cytokine levels before treatment and 3, 6, and 12 months after the start of therapy.

lymphocyte proliferation has been also observed after 6 and 12 months of the treatment (blood samples were collected in October and January, respectively).

\section{IFN- $\gamma /$ IL-4 ratios}

The relative concentrations of IFN $\gamma$ and IL- 4 were calculated (Table 4). Prior to treatment, the cytokine ratios both in sputum and plasma were relatively low (median values, 1.1 and 2.7, respectively). During 6 months of the treatment the cytokine ratios were found to be significantly increased (median values, 16.9 and 4.6 in sputum and plasma, respectively). Over 1 year IFN- $\gamma$ tended to predominate in peripheral blood. With regard to cytokine ratios in sputum, they could not be calculated since the IFN- $\gamma$ level became undetectable (See Fig. 2C).

Table 2. Neutrophil elastase activity and protein concentration in the sputa of cystic fibrosis patients during clarithromycin treatment

\begin{tabular}{|c|c|c|c|c|}
\hline & \multicolumn{2}{|c|}{ Elastase } & \multicolumn{2}{|c|}{ Protein } \\
\hline & $\mathrm{U} / \mathrm{mg}$ protein & $p$ & $\mathrm{mg} / \mathrm{ml}$ & $p$ \\
\hline Before treatment & $36.4(0-1660)$ & & $1.5(0.2-9.9)$ & \\
\hline 3 months after treatment & $39.1(0-261.4)$ & 0.28 & $1.7(0.1-6.1)$ & 0.80 \\
\hline 6 months after treatment & $52.4(0-258.9)$ & 0.58 & $1.7(0.7-3.8)$ & 0.40 \\
\hline 12 months after treatment & $57.2(0-260.8)$ & 0.80 & $1.0(0.3-5.3)$ & 0.10 \\
\hline
\end{tabular}

Data are presented as medians (minimum-maximum values). The results were analyzed using a paired Wilcoxon test. 

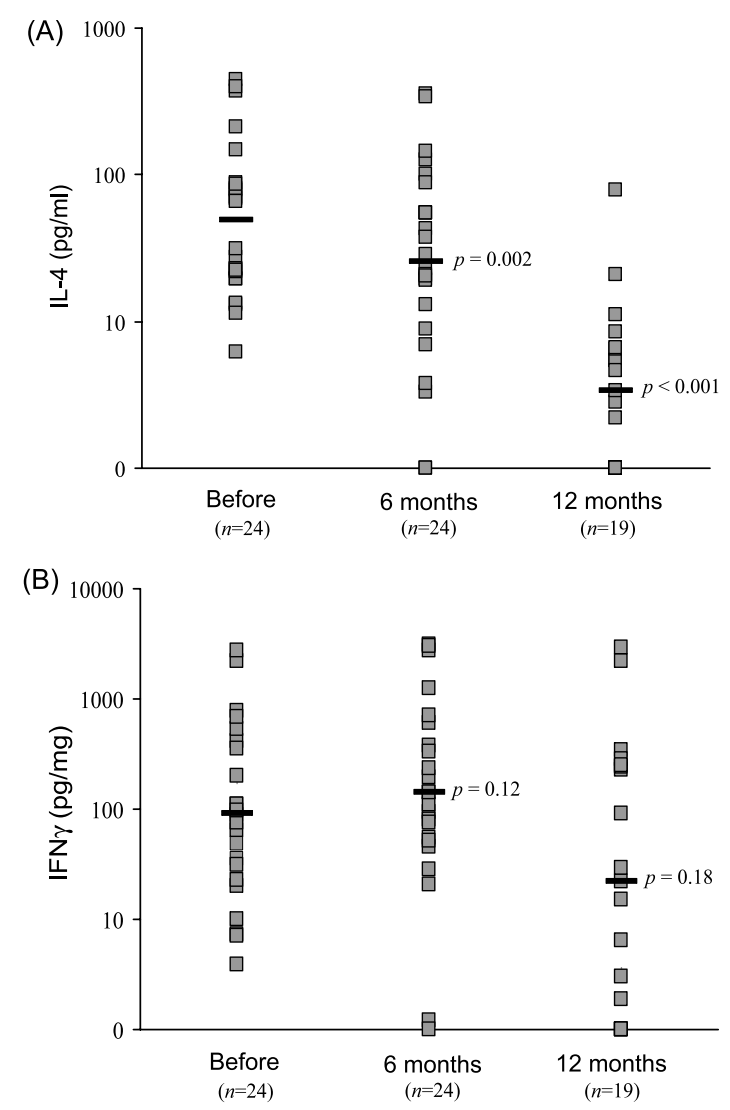

FIG. 3. Cytokine concentrations in the plasma during clarithromycin treatment. Plasma samples were assayed for IL-4 (A) and IFN- $\gamma$ (B). Median values are indicated by the lines. Each dot represents one subject. A two-sample Wilcoxon test was used to compare the cytokine levels before treatment and 6 and 12 months after the start of therapy.

Table 3. Effect of clarithromycin treatment on PHA-induced peripheral blood lymphocyte proliferation

\begin{tabular}{lcc}
\hline & $\begin{array}{c}\text { Proliferative response } \\
\text { (counts/min)* }\end{array}$ & $\begin{array}{c}p \text { value } \\
\text { (Student's } \\
t \text {-test) }\end{array}$ \\
\hline $\begin{array}{l}\text { Before treatment } \\
(n=25)\end{array}$ & $18634 \pm 1587$ & \\
3 months after & $75304 \pm 9817$ & $<0.001$ \\
$\begin{array}{c}\text { treatment }(n=25) \\
\text { months after } \\
\text { treatment }(n=20)\end{array}$ & $39603 \pm 5138$ & 0.001 \\
$\begin{array}{l}1 \text { year after treatment } \\
(n=19)\end{array}$ & $57091 \pm 5622$ & $<0.001$ \\
\hline
\end{tabular}

* Data are presented as the mean \pm standard error of the mean.

\section{Discussion}

According to common opinion, the long-term administration of 14-membered macrolides results in immunosuppression. This opinion is supported by in vitro data of a direct effect on the production of the cytokines involved in the inflammation cascade (decreased production of IL-1, IL-6, IL-8 and TNF- $\alpha$, and increased production of IL-10) $)^{23-25}$ and by ex vivo experiments in animals. ${ }^{26,27}$ In our study a significant decrease of pro-inflammatory IL-8 and TNF- $\alpha$ in the sputum specimens has been found. Moreover, a marked reduction of the regulatory cytokine levels (IL- 4 and IFN- $\gamma$ ) both in the sputum and in peripheral blood was demonstrated. At the same time, the elevation of peripheral blood lymphocyte response to PHA has been observed. This finding contradicts the conclusion about the immunosuppressive effect of long-term macrolide administration.

From the results reported in the literature, there appears to be some agreement that chronic treatment with macrolide antibiotics is effective in cancer. ${ }^{28,29}$ This effect is not associated with direct cytotoxic activity of the drugs, but is a result of enhanced antitumor immunity. Thus, it has been demonstrated that only spleen cells obtained from rats that have been immunized by allogeneic tumor cells followed by clarithromycin treatment showed a detectable cytotoxicity to the tumor cells. ${ }^{30}$ These data and the fact that macrolide prescription in DPB patients is not accompanied by an increase in $P$. aeruginosa colonization $^{14}$ do not support an inference that long-term administration of these drugs results in imunosuppression.

Apparently, the therapeutic effect of macrolides in patients with lung diseases is associated not only with the anti-inflammatory activity of the drugs, but with their immunomodulating properties. Recently, a modulation of Th2 type cytokine production by roxithromycin was shown. Thus, this 14-membered ring macrolide markedly inhibited in vitro both IL-4 and IL- 5 secretion by human peripheral blood T cells in a dose-dependent manner but did not affect T-cell proliferation induced in several ways including anti-

Table 4. Changes of IFN- $\gamma / \mathrm{IL}-4$ ratios during clarithromycin treatment

\begin{tabular}{lccccc}
\hline & \multicolumn{2}{c}{ In sputum } & & \multicolumn{2}{c}{ In plasma } \\
\cline { 2 - 3 } \cline { 5 - 6 } & IFN- $\gamma /$ IL-4 & $p$ & & IFN- $\gamma /$ IL-4 & $p$ \\
\hline Before treatment & $1.1(0-18.9)$ & & & $2.7(0-87.7)$ \\
3 months after treatment & $0.5(0-183.7)$ & 0.32 & & ND & \\
6 months after treatment & $16.9(0-131.4)$ & $<0.001$ & & $4.6(0-798.3)$ & 0.001 \\
12 months after treatment & No calculated* & & $4.4(0-2229.0)$ & 0.067 \\
\hline
\end{tabular}

Data are presented as median (minimum-maximum values).

* The ratio could not be calculated since most patients had an undetectable IFN- $\gamma$ level. 
CD3 antibodies and PMA. ${ }^{31}$ Our data are in accordance with these results. Thus, we succeeded in showing that the long-term clarithromycin treatment is associated with the change of the IFN $\gamma / \mathrm{IL}-4$ ratio in favor of IFN- $\gamma$. Such a shift in the cytokine profile has been observed both in the sputum and in peripheral blood. The increase of PHA-stimulated lymphocyte proliferation has been also demonstrated. This seemed to be additional evidence of the shift towards a Th1 type response following clarithromycin treatment. Obviously, the observed immunological changes are favorable for the patients with CF lung disease. Thus, in our study a significant increase of mean FVC and $\mathrm{FEV}_{1}$ during clarithromycin treatment has been demonstrated. The data are in line with the results of previous studies showing that a Th1dominated immune response might improve the prognosis obtained in CF patients. In particular, a positive correlation between IFN- $\gamma$ production and lung function was found. ${ }^{32}$ Similar results have been obtained in a mouse model of chronic $P$. aeruginosa infection, that a more Th1-dominating response would decrease lung inflammation. The animal mortality due to the infection was significantly lower in $\mathrm{C} 3 \mathrm{H} / \mathrm{HeN}$ mice, known as Th1 responders, compared with $\mathrm{BALB} / \mathrm{c}$, known as Th2 responders. ${ }^{33}$ It was also shown that $\mathrm{C} 3 \mathrm{H} / \mathrm{HeN}$ mice had the highest IFN- $\gamma$ and the lowest IL- 4 production in the lungs compared with the Th2-reacting BALB/c mice. ${ }^{34}$

In conclusion, the beneficial effect of the prolonged treatment of CF patients with a 14-membered ring macrolide antibiotic, clarithromycin, seems to be associated not only with down-regulation of the inflammatory response, but also with immunological changes including the switch from Th2 to Th1 type response.

\section{References}

1. Nelson S, Summer WR, Terry PB, Warr GA, Jacob GJ. Erythromycininduced suppression of pulmonary antibacterial defenses. A potential mechanism of superinfection in the lung. Am Rev Respir Dis 1987; 136: $1207-1212$.

2. Lambro MT, El Benna J, Babin-Chevayé C. Comparison of the in vitro effect of several macrolides on the oxidative burst of human neutrophil. J Antimicrob Chemother 1989; 24: 561-572.

3. Hand WL, Hand D, King-Thomson N. Antibiotic inhibition of the respiratory burst response in human polymorphonuclear leukocytes. Antimicrob Agents Chemother 1990; 34: 863-870

4. Kadota J, Sakito O, Kohno S. A mechanism of erythromycin treatment in patients with diffuse panbronchiolitis. Am Rev Respir Dis 1993; 147: $153-159$.

5. Khair OA, Devalia JL, Abdelaziz MM, Sapsford RJ, Davies RJ. Effect of erythromycin on Haemophilus influenza endotoxin-induced release of IL-6, IL-8 and sICAM-1 in cultured human bronchial epithelial cells. Eur Respir J 1995; 8: 1451-1457.

6. Kawasaki S, Takizawa $\mathrm{H}$, Otoshi $\mathrm{T}$, et al. Roxithromycin inhibits cytokine production by and neutrophil attachment to human bronchial epithelial cells in vitro. Antimicrob Agents Chemother 1998; 42: 14991502 .

7. Shultz MJ, Speelman P, Zaat S, van Deventer SJ, van der Poll T. Erythromycin inhibits tumor necrosis factor- $\alpha$ and interleukin 6 production induced by heat-killed Streptococcus pneumoniae in whole blood. Antimicrob Agents Chemother 1998; 42: 1605-1609.

8. Konno S, Adachi M, Asano K, Kawazoe T, Okamoto K, Takahashi T. Influence of roxithromycin on cell-mediated immune response. Life Sci 1992; 51: PL107-PL112.
9. Konno S, Adachi M, Asano K, Okamoto K, Takahashi T. Anti-allergic activity of roxithromycin: inhibition of interleukin -5 production from mouse T-lymphocytes. Life Sci 1993; 52: PL25-PL30.

10. Hardy RD, Rios AM, Chaves-Bueno S, et al. Antimicrobial and immunologic activities in murine model of Mycoplasma pneumoniaeinduced pneumonia. Antimicrob Agents Chemother 2003; 47: 16401620

11. Labro MT. Anti-inflammatory activity of macrolides: a new therapeutic potential? J Antimicrob Chemother 1998; 41(Suppl B): 37-46.

12. Jaffé A, Bush A. Anti-inflammatory effects of macrolides in lung disease. Pediatr Pulmon 2001; 31: 464-473.

13. Wales D, Woodhead M. The anti-inflammatory effects of macrolides. Thorax 1999; 54(Suppl 2): S58-S62.

14. Yanagihara K, Kadoto J, Kohno S. Diffuse panbronchiolitis - pathophysioligy and treatment mechanisms. Int J Antimicrob Agents 2001; 18: S83-S87.

15. Jaffé A, Francis J, Rosenthal M, Bush A. Long-term azithromycin may improve lung function in children with cystic fibrosis. Lancet 1998; 351: 420 .

16. Pukhalsky A, Shmarina G, Kashirskaja N, Kapranov N, Kokarovtseva S, Lubskaya T. Effet de la clarythromycine sur les paramètres fonctionnels respiratoires et sur le système immunitaire d'enfents atteints de mucoviscidose. Le Pédiatre 2001; 36: 14-18.

17. Walter J, Seeney S, Bell S, Bowler S, Masel P, McCormack J. Effect of long term treatment with azithromycin on disease parameters in cystic fibrosis: a randomized trial. Thorax 2002; 57: 212-216.

18. Equi A, Balfour-Lynn IM, Bush A, Rosenthal M. Long term azythromycin in children with cystic fibrosis: a randomized, placebo-controlled crossover trial. Lancet 2002; 360: 978-984.

19. Darbe A, ed. Practical Protein Chemistry. A Handbook. Cichester: John Wiley \& Sons, 1986

20. Visser L, Blout ER. The use of p-nitrophenyl-N-tetrabutoycarbonyl-Lalaninate for elastase. Bichem Biphys Acta 1972; 268: 257-260.

21. Kaminskaya GA, Zhukova NL, Stepanyan IE. Comparison of two methods for the study of the sputum elastolytic activity and assessment of the results. Lab Delo 1984; 2: 110-113 (in Russian)

22. Ruff MR, Gifford GE. Tumor necrosis factor. In: Pick E, ed. Lymphokines. New York: Academic Press, 1981: 235-241.

23. Takeshita K, Yamagishi I, Harada M, Otomo S, Nakagawa T, Mizushima Y. Immunological and anti-inflammatory effect of clarithromycin: inhibition of interleukin 1 production of murine peritoneal macrophages. Drugs Exp Clin Res 1989; 15: 527-533.

24. Morikawa K, Oseko F, Morikawa S, Iwamoto K. Immunomodulatory effects of three macrolides, midecamycin acetate, josamycin and clarithromycin on human T lymphocyte function in vitro. Antimicrob Agents Chemother 1994; 38: 2643-2647.

25. Morikawa K, Watabe H, Araake M, Morikawa S. Modulatory effect of antibiotics on cytokine production by human monocytes in vitro. Antimicrob Agents Chemother 1996; 40: 1366-1370.

26. Konno S, Adachi M, Asano K, Kawazoe T, Okamoto K, Takahashi T. Influence of roxithromycin on cell-mediated immune responses. Life Sci 1992; 51: PL107-PL112.

27. Konno S, Adachi M, Asano K, Okamoto K, Takahashi T. Anti-allergic activity of roxithromycin: inhibition of interleukin- 5 production from mouse T-lymphocytes. Life Sci 1993; 52: PL25-PL30.

28. Mikasa K, Sawaki M, Kita E, et al. Significant survival benefit to patients with advanced non-small cell lung cancer from treatment with clarithromycin. Chemotherapy 1997; 43: 288-296.

29. Sakamoto M, Mikasa K, Majima T, et al. Anti-cachectic effect of clarithromycin for patients with unresectable non-small cell lung cancer Chemotherapy 2001; 47: 444-451.

30. Sassa K, Mizushima Y, Fujishita T, Oosaki R, Kobayashi M. Therapeutic effect of clarithromycin on a transplanted tumor in rats. Antimicrob Agents Chemother 1999; 43: 67-72.

31. Asano K, Kamakazu K, Hisamitsu T, Suzuki H. Modulation of Th2 type cytokine production from human peripheral blood leukocytes by a macrolide antibiotic, roxithromycin in vitro. Int Immunopharmacol 2001; 1: 1913-1921.

32. Moser C, Kjaergaard S, Pressler T, Kharazmi A, Koch C, Høiby N. The immune response to chronic Pseudomonas aeruginosa lung infection in cystic fibrosis patients is predominantly of the Th-2 type. Acta Pathologica, Microbiologica et Immunologica Scandinavia 2000; 108: $329-335$.

33. Johansen HK, Cryz SJ Jr, Hougen HP, Moser C, Høiby N. Vaccination promotes TH1-like inflammation and survival in chronic Pseudomonas aeruginosa pneumonia. A new prophylactic principle. Behring Inst Mitt 1997; 98: 269-273

34. Moser C, Hougen HP, Song Z, Rygaard J, Kharazmi A, Høiby N. Early immune response in susceptible and resistant mice strains with chronic Pseudomonas aeruginosa lung infection determines the type of T-helper cell response. Acta Pathologica, Microbiologica et Immunologica Scandinavia 1999; 107: 1093-1100.

\section{Received 19 December 2003 \\ Accepted 23 February 2004}

Mediators of Inflammation · Vol 13 2004 


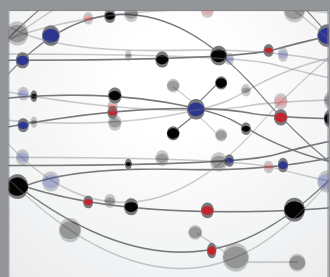

The Scientific World Journal
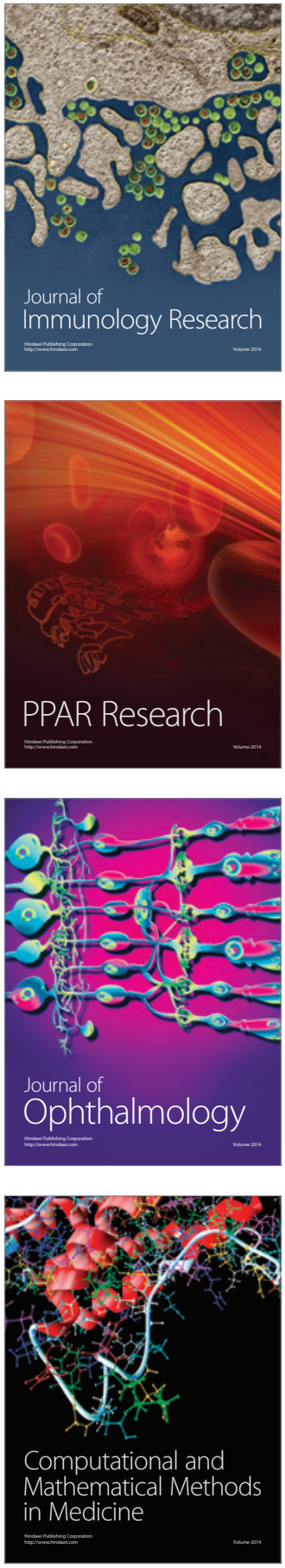

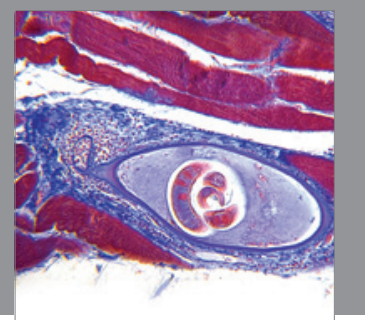

Gastroenterology

Research and Practice
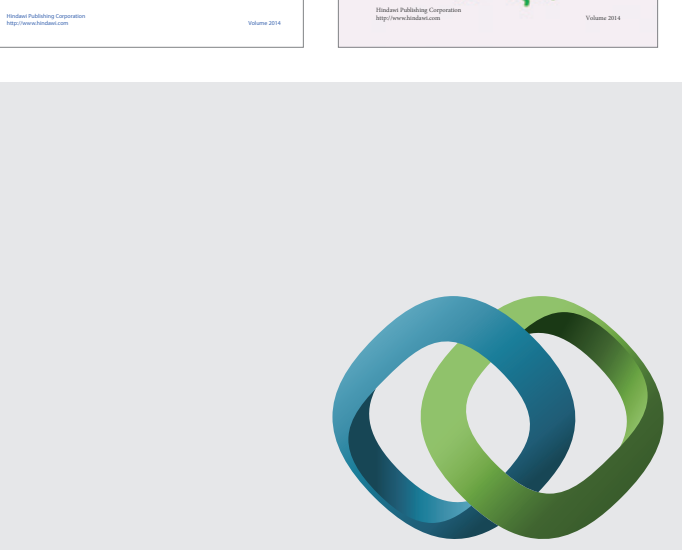

\section{Hindawi}

Submit your manuscripts at

http://www.hindawi.com
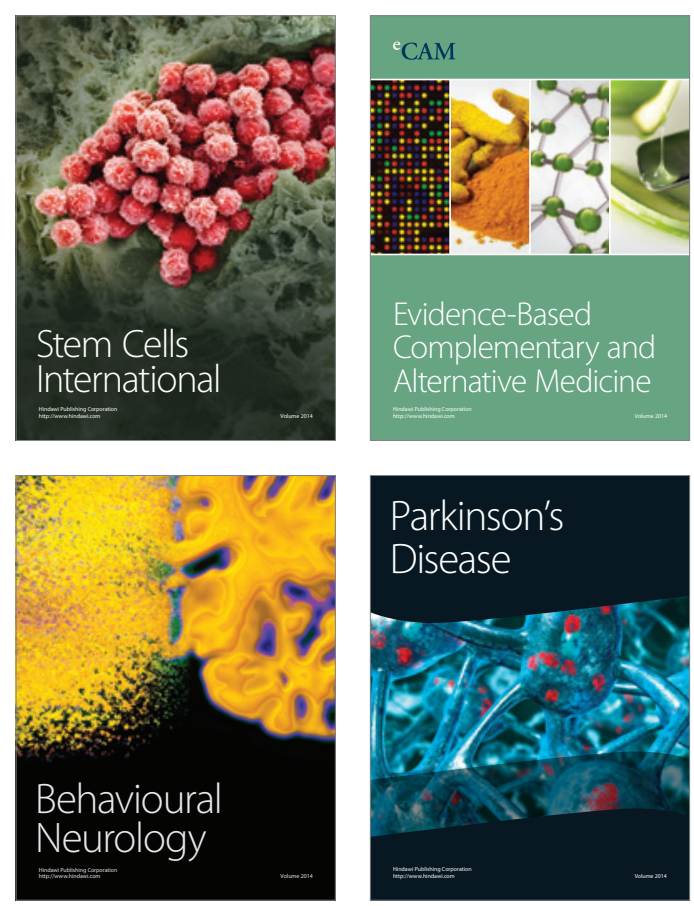

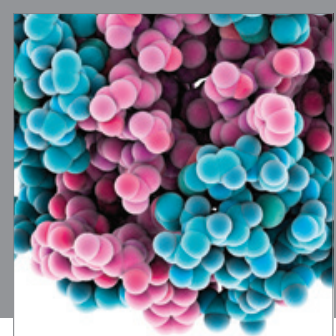

Journal of
Diabetes Research

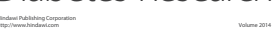

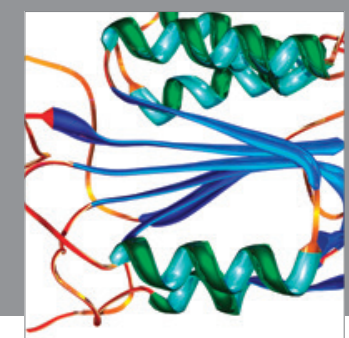

Disease Markers
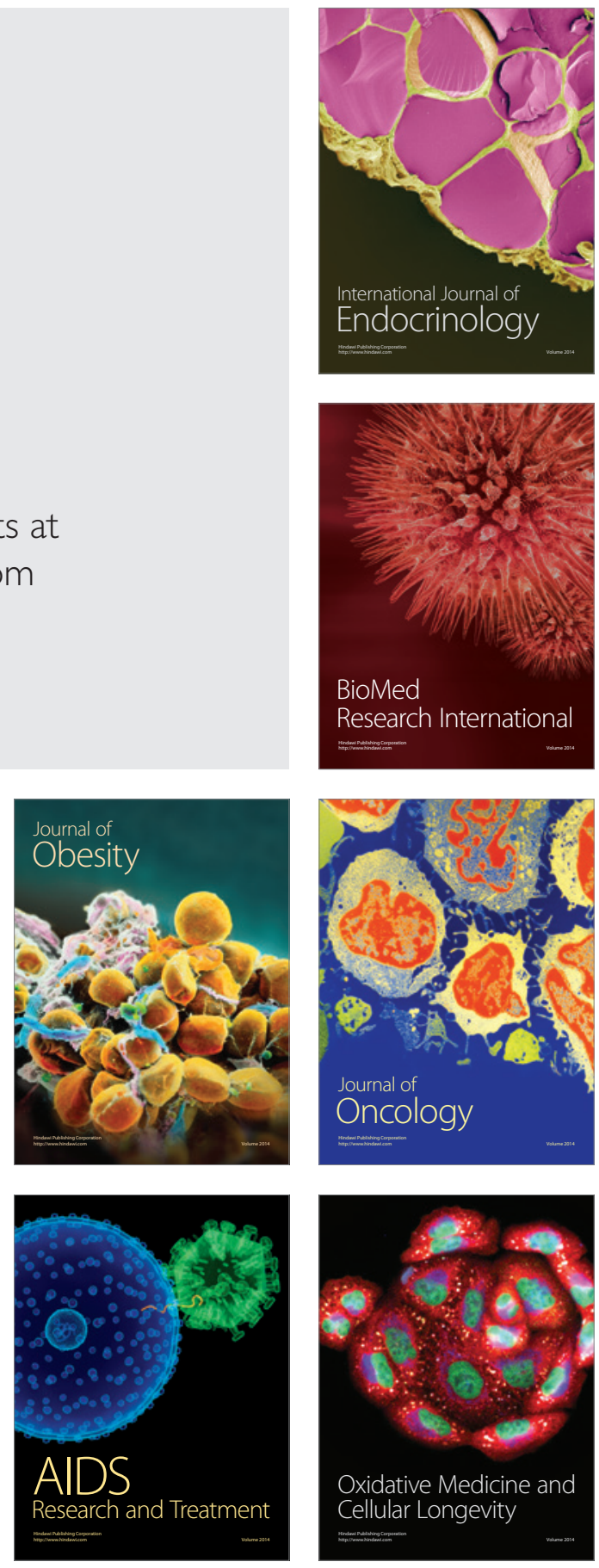